que se banir Sartre, pois a sua leitura é trabalhosa. Na Língua Inglesa excluiríamos Shakespeare pois a sua linguagem está ultrapassada e dá trabalho entendê-lo. Levando um pouco ao limite, podíamos sugerir que fosse retirada a cadeira de Anatomia dos cursos de Medicina; dá muito trabalho. Não sei, depois, que médicos teríamos para nos tratar. O simples facto de algo ser trabalhoso não é argumento que se possa invocar a não ser por má fé ou ignorância.

Num país e num tempo em que ideias erradas são criadas e alimentadas por tantos, é fundamental que aqueles que abraçaram a missão de transmitir os conhecimentos, os professores, não cedam à tentação de seguir a corrente. Sejam professores do $1^{\circ} \mathrm{ciclo}$, $3^{\circ}$ ciclo ou de cursos superiores é necessário e urgente que se dê um sinal de que é possível que as coisas sejam diferentes. É preciso que os alunos continuem a ter as várias opções em aberto, é preciso e necessário que possam entender o mundo que os rodeia, é preciso e necessário que tenham uma cultura completa e equilibrada, é preciso e necessário que saibam que há temas e matérias trabalhosos e que até por isso são muitas vezes mais compensadores.
E é preciso que haja professores que continuem a lutar para que isto aconteça. É preciso e necessário que se mude as mentalidades e que não se deixe o nosso ensino seguir em direcção ao facilitismo, ao estreitamento de horizontes e à ignorância encapotada. Obrigado aos que entenderem esta mensagem, pois, esses sim, estão a construir um melhor futuro para os nossos jovens e para todos nós.

João Paulo Leal Secretário Geral Adjunto Direcção da SPQ

\title{
Final das Olimpíadas de Química.mais 2009
}

A Final realizada no Departamento de Química da Universidade de Aveiro no dia 9 de Maio, foram encontrados os vencedores absolutos das Olimpíadas Portuguesas de Química:

Medalha de Ouro

Bruno Tiago Lopes Carneiro Devesa - Colégio Internato dos Carvalhos

Medalha de Prata

Gonçalo Vitorino Bonifácio - ES José Saramago(Mafra)

Medalha de Bronze

David Armando de Oliveira Pinto - Colégio Internato dos Carvalhos

Juntamente com estes 3 medalhados, foramtambémapurados paraa fase preparatória das competições internacionais de 2010 os seguintes participantes:

- Marta Cristina Neves Aguiar - ES de Homem Cristo (Aveiro) - Alexandre Faia Carvalho - ES/B3 de Peniche Maria de Azevedo António Machado da Silva - ES/B3 de Peniche - Gonçalo Filipe Moura Ferreira - ES de Francisco Rodrigues Lobo (Leiria) - Ana Catarina Rodrigues dos Santos e Silva - Colégio Internato dos Carvalhos - Sergio Bruno Moura Marcos - ES/B3 Rio Tinto Jorge Pedro Martins Nogueiro - ES/B3 Emídio Garcia (Bragança)

O Prémio "Melhor Escola", que distingue a instituição com o melhor conjunto de resultados dos seus 3 participantes foi atribuído ao Colégio Internato dos Carvalhos, que teve dois dos seus alunos medalhados. Os 27 alunos participantes na Final nacio- nal foram apurados nas 3 semifinais realizadas a 14 de Março em Aveiro, Lisboa e Porto.

\section{** Lista dos Participantes na Final ** \\ Vencedores da Semifinal de Aveiro (Departamento de Química, Univer- sidade de Aveiro)}

Medalhas de Ouro

ES de Homem Cristo

Marta Cristina Neves Aguiar

Daniel Martins

Pedro Jorge Vieira

Professor: Maria Fernanda Quinta e Dulcina Carvalho

Medalhas de Prata

ES/B3 de Peniche

Alexandre Faia Carvalho

Maria de Azevedo António Machado da Silva

Geisa Silva Félix

Professor: Maria Leonor Chagas Marques e Manuel Lopes Martins

\section{Medalhas de Bronze}

ES de Francisco Rodrigues Lobo

André Guarda

Gonçalo Filipe Moura Ferreira

João Carlos Marques

Professor: Maria Amélia Moura

Vencedores da Semifinal do Porto (Departamento de Química, Universidade do Porto)

Medalhas de Ouro

Colégio Internato dos Carvalhos

Bruno Tiago Lopes Carneiro Devesa
Ana Catarina R. dos Santos e Silva

David Armando de Oliveira Pinto

Professor: Joaquim Batista da Silva

Medalhas de Prata

ES/B3 Rio Tinto

Sérgio Marcos

Paulo Xavier

Margarida Moura

Professor: Maria José Borges

Medalhas de Bronze

ES/B3 Emídio Garcia - Bragança

Jorge Pedro Martins Nogueiro

Salomão Assis Campo Fernandes

João Pedro Esteves Bragada

Professor: Ana Cristina Ferreira

Vencedores da Semifinal de Lisboa (Instituto Superior Técnico, Universidade Técnica de Lisboa)

Medalhas de Ouro

ES José Saramago - Mafra

Alexandra Castelo

Bianca Rosca

Gonçalo Bonifácio

Professor: Maria Manuela Raposo Martins

Medalhas de Prata

ES Pinheiro e Rosa - Faro

Joana Isabel Afonso

Ana Catarina

Rafael Vieira

Professor: Ana Paula Machado

Medalhas de Bronze

ES Bocage - Setúbal

Carla Viegas

Delfim Costa

Marta Fidalgo

Professor: Maria da Conceição Brito 